\title{
Suspected abdominal compartment syndrome during endoscopic diskectomy - A case report -
}

Received October 12, 2017

Revised 1st, November 21, 2017

2nd, December 18, 2017

3rd, December 28, 2017

Accepted December 31, 2017

\section{Corresponding author}

Kwang Ho Lee, M.D.

Department of Anesthesiology and

Pain Medicine, Yonsei University

Wonju College of Medicine, 20 Ilsan-

ro, Wonju 26426, Korea

Tel: 82-33-741-1526

Fax: 82-33-742-8198

E-mail: khlee6006@yonsei.ac.kr

ORCID

http://orcid.org/0000-0002-1641-1301

\section{Jihyoung Park, Hyun Kyo Lim, June Ho Choi, Woo Jin Choi, Jaemoon Lee, and Kwang Ho Lee}

Department of Anesthesiology and Pain Medicine, Yonsei University Wonju College of Medicine, Wonju, Korea
Abdominal compartment syndrome can produce a critical situation if not diagnosed early and managed properly. We report a case of abdominal compartment syndrome that was caused by massive irrigation of surgical fluid during endoscopic lumbar diskectomy at the L4-L5 level. There was a sudden increase in peak inspiratory pressure during the operation, and the patient's tidal volume and blood pressure decreased. When the patient's position was changed from prone to supine, abdominal distension and cyanosis of both lower extremities were discovered. Ultrasonic findings showed fluid collection in both the chest and intra-abdominal cavity. Thoracentesis and abdominal decompression surgery were performed, and the patient's overall state improved. We concluded that irrigation fluid used during the endoscopic operation leaked into the retroperitoneal space and caused abdominal compartment syndrome.

Key Words: Abdominal compartment syndrome, Diskectomy, Endoscopy.
Incisions made in endoscopic operations are small, decreasing tissue damage and speeding recovery. Endoscopic techniques are therefore widely used in various surgeries, including knee and shoulder joint surgery and vertebral disc operations. However, it is necessary to use a large amount of irrigation fluid to obtain a surgical view during endoscopy, and this fluid can extravasate into the surrounding tissues.

Abdominal compartment syndrome (ACS) is a serious condition that causes multi-organ dysfunction because of increased intra-abdominal pressure (IAP). Many factors such as abdominal bleeding, ascites, and intestinal obstruction can lead to an increase in IAP.

ACS has been reported in critically ill patients [1], patients who underwent transurethral resection of the prostate [2], those with aortic aneurysm rupture [3], and trauma patients [4]. ACS caused by endoscopic diskectomy, however, is rare
[5]. We present a case of ACS caused by irrigation fluid leakage during percutaneous endoscopic diskectomy that was accompanied by acute respiratory insufficiency and hemodynamic collapse.

\section{CASE REPORT}

A 75-year-old female patient (height: $150 \mathrm{~cm}$, weight: $44 \mathrm{~kg}$ ) was admitted for lower back pain, a tingling sensation in both calves, and left calf numbness. She was scheduled for left L5S1 level laminectomy, diskectomy (compression fracture at the L4 level, L5-S1 level posterolateral disc herniation) and right L4-5 level endoscopic diskectomy (L4-5 level extraforaminal disc herniation).

There was no specific disease except hypertension. Preoperative electrocardiography showed normal sinus rhythm

This is an Open Access article distributed under the terms of the Creative Commons Attribution Non-Commercial License (http://creativecommons.org/licenses/by-nc/4.0) which permits unrestricted non-commercial use, distribution, and reproduction in any medium, provided the original work is properly cited.

Copyright (C) the Korean Society of Anesthesiologists, 2018 
with left ventricular hypertrophy. Chest X-ray (Fig. 1A) and pulmonary function tests were within normal limits. Upon arrival at the operating room, her blood pressure was 159/80 $\mathrm{mmHg}$, heart rate was 107 beats/min, and peripheral oxygen $\left(\mathrm{O}_{2}\right)$ saturation was $99 \%$. Routine monitoring was conducted and included measurement of non-invasive blood pressure, electrocardiography, peripheral oxygen saturation, transesophageal temperature, bispectral index, and endtidal carbon dioxide. Anesthesia was induced with $150 \mathrm{mg}$ of thiopental sodium and $50 \mathrm{mg}$ of rocuronium. Anesthesia was maintained with desflurame (4.5-6.0 vol\%), remifentanil 0.02 $\mu \mathrm{g} / \mathrm{kg} / \mathrm{min}$ with target bispectral index from 40 to 60 , and end tidal $\mathrm{CO}_{2}$ between 35 and $40 \mathrm{mmHg}$. Arterial cannulation was performed after the modified Allen test for continuous arterial blood pressure monitoring. The patient's position was changed from supine to prone for surgery.

After left L5-S1 laminectomy and diskectomy surgery, transforaminal percutaneous endoscopic diskectomy at right L4-5 was performed. During the operation, irrigation pressure was increased from $40 \mathrm{mmHg}$ to $60 \mathrm{mmHg}$ to obtain a surgical view. One hour into the endoscopic operation, the patient's peak inspiratory pressure (PIP) increased from 22 $\mathrm{cmH}_{2} \mathrm{O}$ to $40 \mathrm{cmH}_{2} \mathrm{O}$. Furthermore, expired tidal volume decreased from $350 \mathrm{ml}$ to $200 \mathrm{ml}\left(\mathrm{FiO}_{2}: 0.5\right.$, tidal volume: 350 $\mathrm{ml}$, respiratory rate: 16 breaths/min, positive end-expiratory pressure [PEEP]: $5 \mathrm{mmHg}$ ) and transesophageal temperature from $35.5^{\circ} \mathrm{C}$ to $33.5^{\circ} \mathrm{C}$. The circuit and endotracheal tube were checked for kinks and obstructions, but none were found. On auscultation, the left-side lung sound was dominant compared to the right-side lung. Tidal volume was below $110 \mathrm{ml}$ when pressure-controlled ventilation mode was applied with a PIP setting of $25 \mathrm{cmH}_{2} \mathrm{O}$. The endotracheal tube was with- drawn from $21 \mathrm{~cm}$ to $20 \mathrm{~cm}$ from the incisor, but the left-side lung sound remained dominant. Blood pressure decreased to $80 / 60 \mathrm{mmHg}$, heart rate was 90 beats/min, and peripheral $\mathrm{O}_{2}$ saturation decreased from $100 \%$ to $95 \%$. Manual lung recruitment was performed, but only $200 \mathrm{ml}$ of expired tidal volume was obtained.

Chest X-ray (Fig. 1B) 30 minutes after the increase in airway pressure showed haziness in both lungs, with the endotracheal tube tip located at the trachea. Blood pressure was continuously measured and found to be low at about 75/60 $\mathrm{mmHg}$, with a heart rate of 90 beats/min; ephedrine was given intravenously. Tidal volume of the ventilator could not be maintained properly due to the high airway pressure, and the operation was concluded 20 minutes later. Endoscopic diskectomy was conducted for 1 hour 40 minutes, and the patient's position was changed to supine. During endoscopic diskectomy, $15 \mathrm{~L}$ of normal saline was used as irrigation fluid, and urine output decreased from $60 \mathrm{ml}$ to $30 \mathrm{ml}$ per hour. The patient's abdomen was distended, and both legs showed cyanotic changes. Heart sound was maximally heard at the left 3rd intercostal space, mid-axillary line. PIP increased to $49 \mathrm{cmH}_{2} \mathrm{O}$, and expired tidal volume was less than $100 \mathrm{ml}$ $\left(\mathrm{FiO}_{2}: 1.0\right.$, tidal volume: $250 \mathrm{ml}$, respiratory rate: 16 breaths/ min, PEEP: $0 \mathrm{mmHg}$ ). Peripheral $\mathrm{O}_{2}$ saturation decreased to $90 \%$, and blood pressure was $66 / 48 \mathrm{mmHg}$ with a heart rate of 93 beats/min, for which phenylephrine intravenous infusion was started.

Ultrasonography revealed a massive amount of fluid in the chest (Fig. 2A) and abdominal cavity (Fig. 2B). After clear fluid drainage was confirmed, thoracentesis was performed with a vascular access catheter (Arrow Blue FlexTip ${ }^{\circledR}$, Arrow International Inc., USA) at the right posterior axillary line around
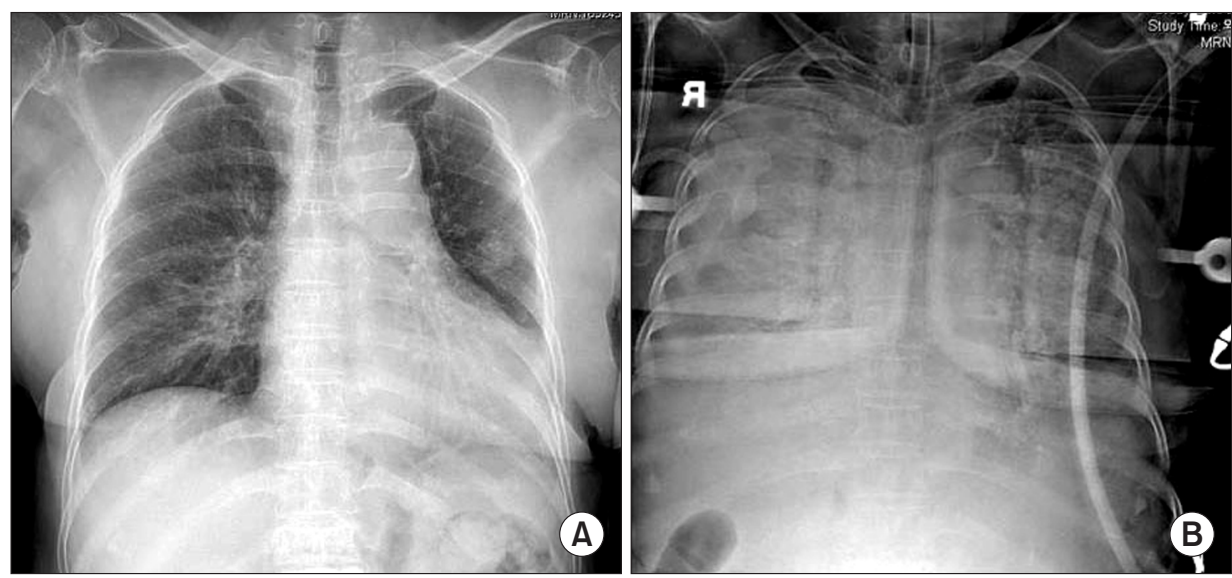

Fig. 1. Chest radiograph. (A) Preoperative chest X-ray (posteroanterior view) shows normal. (B) Chest X-ray (anteroposterior view) shows haziness in both lung field 30 minutes after the increase in airway pressure. 

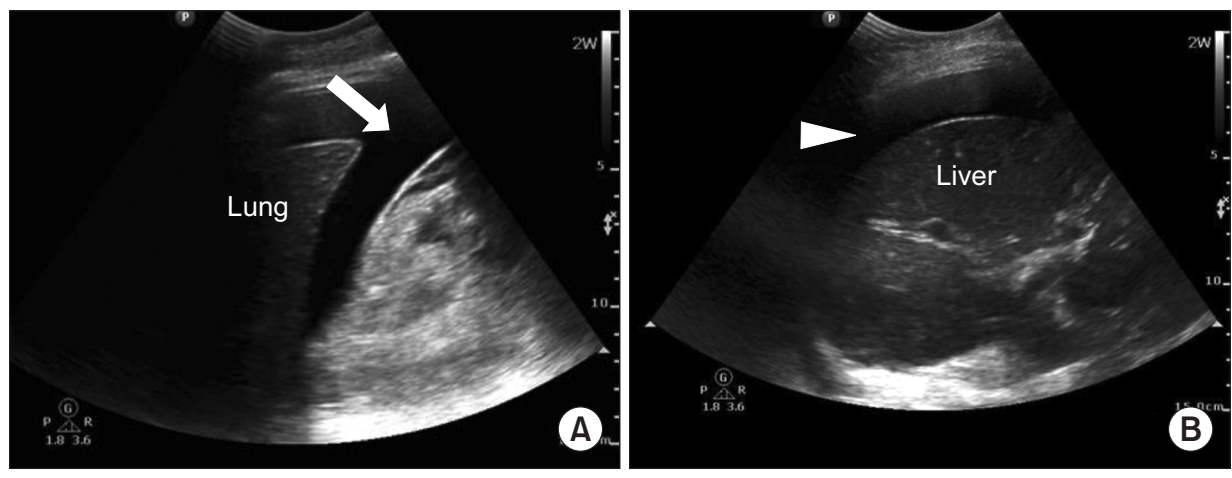

Fig. 2. (A) Ultrasonographic image at the right posterior axillary line around the lower tip of the scapula. Fluid collection of $2.8 \mathrm{~cm}$ width was observed in the pleural cavity (arrow). (B) Ultrasonographic image at the right middle axillary line around the lower tip of the scapula. Fluid collection of $2 \mathrm{~cm}$ width was observed in the right upper quadrant of the abdominal cavity (arrow head).

the lower tip of the scapula. A total of $400 \mathrm{ml}$ of clear fluid was drained from the thoracic cavity through the catheter. After thoracentesis, PIP decreased to $33 \mathrm{cmH}_{2} \mathrm{O}$, expired tidal volume increased to $220 \mathrm{ml}$, and peripheral $\mathrm{O}_{2}$ saturation increased to $100 \%\left(\mathrm{FiO}_{2}: 0.6\right.$, tidal volume: $250 \mathrm{ml}$, respiratory rate: 16 breaths/min, PEEP: $3 \mathrm{mmHg}$ ). We considered ACS caused by irrigation fluid and decided to perform an abdominal decompressive operation. Analysis of arterial blood gas revealed a $\mathrm{pH}$ of $6.98, \mathrm{PO}_{2}$ of $95 \mathrm{mmHg}, \mathrm{PCO}_{2}$ of $59 \mathrm{mmHg}$, hemoglobin ( $\mathrm{Hb}$ ) of $11.2 \mathrm{~g} / \mathrm{dl}$, hematocrit (Hct) of $31 \%, \mathrm{Na}^{+}$ of $140 \mathrm{mmol} / \mathrm{L}, \mathrm{K}^{+}$of $2.8 \mathrm{mmol} / \mathrm{L}$, and $\mathrm{Ca}^{2+}$ of $0.80 \mathrm{mmol} / \mathrm{L}$. Thirty minutes after diagnosis, laparotomy was performed, and $2 \mathrm{~L}$ of clear fluid was removed from the abdominal cavity. PIP decreased immediately to $29 \mathrm{cmH}_{2} \mathrm{O}$, and $\mathrm{O}_{2}$ saturation was maintained at $100 \%$.

After the operation, cyanosis in both legs improved. Arterial blood gas analysis revealed $\mathrm{pH} 7.16, \mathrm{PO}_{2} 203 \mathrm{mmHg}, \mathrm{PCO}_{2}$ $36 \mathrm{mmHg}, \mathrm{Hb} 11.5 \mathrm{~g} / \mathrm{dl}$, and Hct 32\%. Fluid in the abdominal cavity was removed, but the fluid in the retroperitoneal cavity remained, so the patient was transferred to the ICU with an open incision site, because IAP can increase if abdominal closure is performed instantly. In the ICU, assist/control ventilation mode $\left(\mathrm{FiO}_{2}: 0.6\right.$, tidal volume: $270 \mathrm{ml}$, respiratory rate: 16 breaths/min, PEEP: $6 \mathrm{mmHg}$ ) was maintained. Post-op day 1 , a chest X-ray showed improved haziness, and arterial blood gas analysis at $\mathrm{FIO}_{2} 0.4$ revealed $\mathrm{pH} 7.42, \mathrm{PO}_{2} 145 \mathrm{mmHg}$, and $\mathrm{PCO}_{2} 32 \mathrm{mmHg}$. Abdominal wound closure was performed on post-op day 2 , and extubation was conducted on post-op day 3.

\section{DISCUSSION}

Endoscopic diskectomy is a minimally invasive surgical technique for relieving symptoms such as back pain or leg numbness. This technique requires use of irrigation fluid, which can leak through damaged tissues. Ahn et al. [6] reported that postoperative retroperitoneal hematoma occurs in $1 \%$ of patients undergoing transforaminal percutaneous endoscopic lumbar diskectomy. In our case, posterolateral endoscopic diskectomy was attempted, and the incision was made $10 \mathrm{~cm}$ lateral from the posterior midline. Such an approach is unlikely to have resulted in direct peritoneal perforation. Furthermore, a large quantity of clear fluid was found in both the chest and abdominal cavities, which implies that irrigation fluid, not bleeding, was the cause of ACS. We believe that, during the procedure, irrigation fluid permeated through damaged muscles and tissues and entered the retroperitoneal space and abdominal cavity, causing ACS. Increasing irrigation pressure to $60 \mathrm{mmHg}$ during the operation to procure a better surgical view could have accelerated leakage of irrigation fluid into cavities.

ACS causes circulatory dysfunction by increasing abdominal pressure and reducing peripheral tissue perfusion. Other features of ACS include a distended abdomen, increased PIP, and oliguria. Normal abdominal pressure is below $0 \mathrm{mmHg}$. A pressure of $10 \mathrm{mmHg}$ reduces hepatic arterial blood flow, a pressure between 15-20 mmHg causes adverse cardiovascular changes, and a pressure above $40 \mathrm{mmHg}$ cause oliguria [7]. Therefore, if diagnosis and treatment are delayed, decreased cardiac output, pulmonary atelectasis, and decreased intestinal perfusion can occur, leading to catastrophic result. In adults, an IAP above $25 \mathrm{mmHg}$ is an indication of abdominal decompression. Kron et al. [8] reported that, by measuring urinary bladder pressure, it is possible to estimate abdominal pressure. Meldrum et al. [9] reported that a bladder pressure between $26-35 \mathrm{mmHg}$ led to $65 \%$, 78\%, and 65\% renal, pul- 
monary, and cardiovascular compromise, respectively. All patients whose bladder pressure increased over $35 \mathrm{mmHg}$ showed renal, pulmonary, and cardiovascular dysfunction.

IAP was not measured in our patient. However, we suspected abdominal compartment syndrome when considering her clinical signs: PIP of $49 \mathrm{mmHg}$, decreased blood pressure and urine output, abdominal distension and cyanosis of lower extremities. Even though pressure control mode ventilation was used, the tidal volume was only $100 \mathrm{ml}$, and the patient's blood pressure was very low $(66 / 48 \mathrm{mmHg})$, implying decreased cardiac output. If we had not performed a laparotomy operation immediately, the patient's condition could have become life-threatening. Recognizing ACS is not difficult if certain clinical symptoms are observed. Patients with history of abdominal trauma, hemorrhage, or bowel distension have higher risk of ACS; thus, an earlier diagnosis can be made. Diagnosing our patient was difficult at first because an endoscopic diskectomy operation is not an invasive procedure, and the positioning of the patient (prone in this case) and surgical draping made it hard to observe abdominal distension. However, clinical signs such as a tensely distended abdomen, high PIP, cyanosis of the lower extremities, decreased blood pressure, and oliguria led to a diagnosis of ACS. Furthermore, intra-operative chest AP and ultrasonographic findings showed pleural and abdominal fluid collection, which confirmed ACS. As soon as ACS was diagnosed, thoracentesis and laparotomy decompression were performed. Soon after, the patient's airway pressure decreased, and cardiopulmonary function recovered dramatically.

In conclusion, ACS during endoscopic diskectomy is very rare. Nevertheless, it is important to be aware of the possibility of ACS, as late detection of this condition can lead to lifethreatening complications. ACS should be considered especially when there is sudden increase in PIP intra-operatively, along with oliguria and unstable blood pressure. If ACS is suspected, early diagnosis and successful surgical intervention to lower IAP are of utmost importance to ensure the patient's safety.

\section{REFERENCES}

1. Zhang HY, Liu D, Tang H, Sun SJ, Ai SM, Yang WQ, et al. Prevalence and diagnosis rate of intra-abdominal hypertension in critically ill adult patients: a single-center cross-sectional study. Chin J Traumatol 2015; 18: 352-6.

2. Gaut MM, Ortiz J. Management of abdominal compartment syndrome after transurethral resection of the prostate. Braz J Anesthesiol 2015; 65: 519-21.

3. Rubenstein C, Bietz G, Davenport DL, Winkler M, Endean ED. Abdominal compartment syndrome associated with endovascular and open repair of ruptured abdominal aortic aneurysms. J Vasc Surg 2015; 61: 648-54.

4. Koo BK, Kim ST. Anesthetic management of a patient with abdominal compartment syndrome: a case report. Korean J Anesthesiol 2007; 52: 111-4

5. Hilbert T, Boehm O, Pflugmacher R, Wirtz DC, Baumgarten G, Knuefermann P. Rare complication after endoscopic discectomy. 2014; 63: 41-6.

6. Ahn Y, Kim JU, Lee BH, Lee SH, Park JD, Hong DH, et al. Postoperative retroperitoneal hematoma following transforminal percutaneous endoscopic lumbar discectomy. J Neurosurg Spine 2009; 10: 595-602.

7. Schein M, Wittmann DH, Aprahamian CC, Condon RE. The abdominal compartment syndrome: the physiological and clinical consequences of elevated intra-abdominal pressure. J Am Col Surg 1995; 180: 745-53.

8. Kron IL, Harman PK, Nolan SP. The measurement of intraabdominal pressure as a criterion for abdominal re-exploration. Ann Surg 1984; 199: 28-30.

9. Meldrum DR, Moore FA, Moore EE, Franciose RJ, Sauaia A, Burch JM. Prospective characterization and selective management of the abdominal compartment syndrome. Am J Surgery 1997; 174: 667-72; discussion 672-3. 